\title{
Racial and ethnic differences in capecitabine toxicity in patients with gastrointestinal tract cancers
}

\author{
Alicia Brazelton a*, Soham Yande ${ }^{a *}$, Rita Pope $^{\mathrm{b}}$, Michael L. Johnson ${ }^{\mathrm{a}}$, Benjamin Musherb, \\ Meghana V. Trivedia,b \\ University of Houston College of Pharmacy; Dan L. Duncan Comprehensive Cancer Center, Baylor College of \\ Medicine, Houston, TX, USA
}

\section{Abstract}

${ }^{a}$ University of Houston College of Pharmacy, Houston, TX, USA (Alicia Brazelton, Soham Yande, Michael Johnson, Meghana V. Trivedi); ' Dan L Duncan Comprehensive Cancer Center, Baylor College of Medicine, Houston, TX, USA (Rita Pope, Benjamin Musher, Meghana V. Trivedi)

${ }^{*}$ Co-first author

Conflict of Interest: None

Correspondence to: Meghana V. Trivedi, PharmD, PhD, Associate Professor, Department of Pharmacy Practice and Translational Research, University of Houston, Health 2, 4849 Calhoun St., Houston, TX 77204, USA, e-mail: mtrivedi@uh.edu

Received 22 January 2021; accepted 9 March 2021; published online 15 February 2022

DOI: https://doi.org/10.20524/aog.2022.0688

\section{Introduction}

Capecitabine is an oral prodrug of 5-fluorouracil (5-FU) used as monotherapy, concurrently with radiation, or in combination with other antineoplastic agents for multiple gastrointestinal (GI) tract malignancies, including colorectal, gastroesophageal and pancreatobiliary cancers [1-4]. In contrast to infusional 5-FU, capecitabine obviates the need for an indwelling port and 46-h infusion, but it carries potential toxicities that can be life-threatening if not treated early [4]. The most common side-effects of capecitabine when given at full systemic doses (1000 mg/m² b.i.d. for days $1-14$ of a 21-day cycle [5]) are diarrhea and hand-foot syndrome (HFS), which presents with redness, swelling, pain, and even desquamation of the palms and 
soles $[5,6]$. In fact, as many as $50 \%$ of patients on capecitabine monotherapy experience GI toxicity and HFS $[7,8]$, which can be severe enough to warrant dose reductions, delays, and/or discontinuation $[1,2]$. Severe toxicity occurs in $\sim 15 \%$ of patients treated with capecitabine [9], but to date no biomarkers to predict toxicity have been identified. Being able to risk-stratify patients for capecitabine-related toxicity may help clinicians tailor therapy more reliably and safely.

Previous studies have reported a variable response to cancer treatment based on race and ethnicity [10-16]. Similarly, pharmacogenetic factors may contribute to differences in drug metabolism or clearance and therefore chemotherapy-related toxicities $[17,18]$. For example, several gene polymorphisms in $D P Y D$, the gene encoding the dihydropyrimidine dehydrogenase (DPD) enzyme responsible for degrading 5-FU [19], are associated with an increased risk of severe toxicities with 5-FU-based therapy [20-26]. Recently the European Society of Medical Oncology (ESMO) published guidelines for germline $D P Y D$ testing prior to starting fluoropyrimidine therapy [27]. Individuals of certain ancestries are more or less likely to carry $D P Y D$ variants, or to have reduced DPD enzyme activity and a higher risk of 5-FU-related toxicity [28-33]. However, these studies have mostly evaluated bone marrow suppression as a major 5-FU-related toxicity in various populations. While racial and ethnic differences in capecitabine toxicities of diarrhea and HFS have been suggested in case reports [34-37], they have not been systematically evaluated in a diverse, "real-world" population. The purpose of this study was to identify differences in the toxicity profile of capecitabine among patients with different racial and ethnic backgrounds.

\section{Patients and methods}

\section{Patients}

This study was a retrospective analysis of patients with GI malignancies treated with capecitabine-containing chemotherapy at Ben Taub Hospital, a public hospital serving Harris County's underserved population, between January 2012 and July 2017. This protocol was approved by the Institutional Review Boards at Baylor College of Medicine and the University of Houston.

The study population was patients with early or advanced stages of a GI malignancy undergoing first-line treatment with capecitabine-containing chemotherapy. Patients were excluded if they were undergoing treatment with overlapping toxicities (such as irinotecan or radiation, both of which can cause diarrhea) or if they had insufficient clinical data.

\section{Data collection}

Baseline patient demographics and characteristics (race/ ethnicity, sex, age at diagnosis, cancer type, and stage at diagnosis) were extracted using the EPIC electronic medical record system at Ben Taub Hospital, Houston, TX, USA. The patients were categorized into the following race/ethnicity categories: Caucasian/non-Hispanic, Caucasian/Hispanic, African American/non-Hispanic, and other. Each adverse event was documented as written by the treating physician in the patient's chart. We also documented dose reductions and discontinuation of therapy due to side-effects. Since the grades of diarrhea and HFS were not documented for all patients, the severity of toxicity could not be documented objectively in many cases.

\section{Statistical analysis}

We used descriptive analysis to identify the patient demographics (race/ethnicity, sex, age at diagnosis, and stage at diagnosis) (Table 1). Adjusted logistic regression assessed the association between race/ethnicity and any adverse event, HFS, diarrhea, dose reduction, and discontinuation due to side effects, while controlling for age, sex, and stage at diagnosis.

\section{Results}

\section{Baseline characteristics}

Of the 769 patients' charts screened, 125 met the eligibility criterion of receiving capecitabine-containing regimens (except those containing irinotecan and radiation) in the first-line setting for the GI malignancy. The majority of patients excluded from the study were on second- or subsequent line therapies. Baseline characteristics are summarized in Table 1. Of these 125 patients, 40 (32\%) were Caucasian/Hispanic, 47 (38\%) were African American/non-Hispanic, and 38 (30\%) were Caucasian/ non-Hispanic. Underlying GI malignancies were colon ( $\mathrm{N}=76$, $60.8 \%)$, rectal $(\mathrm{N}=22,17.6 \%)$, gastric $(\mathrm{N}=16,12.8 \%)$, or other $(\mathrm{N}=11,8.8 \%)$. Within different racial and ethnic groups, there was no significant difference in the proportions of males and females, age at diagnosis, cancer diagnosis, or stage at diagnosis.

\section{Predictors of capecitabine toxicities}

African Americans were significantly less likely to have diarrhea (odds ratio [OR] 0.25, 95\% confidence interval [CI] 0.08-0.75; $\mathrm{P}=0.01$ ) than Caucasian/non-Hispanic patients (Table 2). Diarrhea incidence was not different between Caucasian/Hispanics and Caucasian/non-Hispanics. Females (OR 3.85, 95\%CI 1.5-8.67; $\mathrm{P}=0.004$ ) were significantly more likely to have diarrhea than males. There was a trend for a greater risk of HFS in African-American/non-Hispanic (OR 2.26, 95\%CI 0.86-5.95; $\mathrm{P}=0.09$ ), although this result did not reach statistical significance (Table 3 ). Discontinuation due to side-effects was numerically more common in Caucasian/ Hispanic patients (OR 1.97, 95\%CI 0.71-5.48; P=0.19) (Table 4) compared to Caucasian/non-Hispanics, but this difference was not statistically significant. Dose reductions due to side-effects 
Table 1 Descriptive characteristics stratified by race/ethnicity

\begin{tabular}{|c|c|c|c|c|}
\hline Race/Ethnicity & African American/non-Hispanic & Caucasian/Hispanic & Caucasian/non-Hispanic & P-value \\
\hline Number (\%) & $47(37.60)$ & $40(32)$ & $38(30.40)$ & 0.58 \\
\hline \multicolumn{5}{|l|}{ Sex } \\
\hline Female & 27 & 15 & 14 & 0.08 \\
\hline Male & 20 & 25 & 24 & \\
\hline \multicolumn{5}{|c|}{ Age at diagnosis (years) } \\
\hline Median (range) & $56.55(37-74)$ & $53.25(35-80)$ & $55.92(39-74)$ & 0.19 \\
\hline \multicolumn{5}{|l|}{ Diagnosis } \\
\hline Colon & 36 & 20 & 20 & 0.06 \\
\hline Rectal & 3 & 7 & 12 & \\
\hline Gastric & 5 & 10 & 1 & \\
\hline Other & 3 & 3 & 5 & \\
\hline \multicolumn{5}{|l|}{ Stage at diagnosis } \\
\hline 1 & 1 & 0 & 0 & 0.46 \\
\hline 2 & 7 & 6 & 5 & \\
\hline 3 & 25 & 13 & 17 & \\
\hline 4 & 14 & 19 & 16 & \\
\hline
\end{tabular}

Table 2 Factors associated with diarrhea

\begin{tabular}{lccc}
\hline Parameter & $\begin{array}{c}\text { Parameter } \\
\text { estimates }\end{array}$ & $\begin{array}{c}\text { Odds } \\
\text { ratio }(95 \% \mathrm{CI})\end{array}$ & P-value \\
\hline Age at diagnosis & 0.003 & $1.00(0.95-1.05)$ & 0.89 \\
$\begin{array}{l}\text { Sex } \\
\text { Female }\end{array}$ & $\begin{array}{c}\text { 1.35 } \\
\text { Male }\end{array}$ & $\begin{array}{c}3.85(1.60-9.26) \\
\text { ref }\end{array}$ & 0.002 \\
$\begin{array}{l}\text { Race/Ethnicity } \\
\text { African American/ } \\
\text { non-Hispanic }\end{array}$ & -1.34 & $0.25(0.08-0.75)$ & 0.01 \\
$\begin{array}{l}\text { Caucasian/Hispanic } \\
\text { Caucasian/ }\end{array}$ & 0.3 & $1.35(0.51-3.56)$ & 0.53 \\
non-Hispanic & ref & ref & \\
$\begin{array}{l}\text { Stage } \\
\text { Stage 2 }\end{array}$ & 0.6 & $1.83(0.54-6.11)$ & 0.32 \\
Stage 3 & 0.54 & $1.72(0.69-4.28)$ & 0.23 \\
Stage 4 & ref & ref & \\
\hline
\end{tabular}

CI, confidence interval

were significantly more common in African American/nonHispanics (OR 5.83, 95\%CI 1.49-22.80; $\mathrm{P}=0.01$ ) and Caucasian/ Hispanics (OR 4.49, 95\%CI 1.09-18.42; $\mathrm{P}=0.03$ ) compared to Caucasians/non-Hispanics (Table 5). Dose reductions were more common in patients who had HFS (48.65\%) compared to those experiencing diarrhea (25.26\%).

\section{Discussion}

We have identified some racial and ethnic differences in the incidence of capecitabine toxicities and related dose reductions in patients with GI malignancies. We found that African Americans had a lower incidence of diarrhea as compared to non-Hispanic Caucasians. While discontinuation due to side effects trended towards being more common in non-Hispanic
Table 3 Factors associated with hand-foot syndrome

\begin{tabular}{lccc}
\hline Parameter & $\begin{array}{c}\text { Parameter } \\
\text { estimates }\end{array}$ & $\begin{array}{c}\text { Odds } \\
\text { ratio (95\%CI) }\end{array}$ & P-value \\
\hline Age at diagnosis & -0.00155 & $0.99(0.95-1.04)$ & 0.94 \\
$\begin{array}{l}\text { Sex } \\
\text { Female }\end{array}$ & -0.5 & $0.6(0.25-1.44)$ & 0.24 \\
$\quad$ Male & ref & ref & \\
Race/Ethnicity & & & \\
African American/ & 0.81 & $2.26(0.86-5.95)$ & 0.09 \\
non-Hispanic & & & \\
Caucasian/Hispanic & -0.45 & $0.63(0.20-1.95)$ & 0.42 \\
Caucasian/ & & ref & \\
$\quad$ non-Hispanic & ref & & \\
Stage & & & \\
$\quad$ Stage 2 & -0.12 & $0.88(0.23-3.29)$ & 0.85 \\
Stage 3 & 0.59 & $1.81(0.74-4.40)$ & 0.18 \\
$\quad$ Stage 4 & ref & ref & \\
\hline
\end{tabular}

CI, confidence interval

Caucasians, dose reductions were significantly more frequent in African Americans and Hispanics compared to nonHispanic Caucasians. The reasons for these differences could not be assessed in our study.

Our finding of a lower incidence of diarrhea in African Americans compared to non-Hispanic Caucasians is concordant with a previous report of inter-racial differences in diarrhea and other GI toxicities of 5-FU-based chemotherapy [33]. The reason underlying the higher incidence of diarrhea among Caucasians when compared to African Americans is unclear. Germline polymorphisms in genes responsible for 5-FU metabolism could potentially explain interracial differences in the prevalence of capecitabine-induced toxicities. Another explanation could be differential reporting and recording of treatment-related toxicities between different racial groups; this should be evaluated in future studies. Patients on second-line capecitabine and those receiving therapies with overlapping 
Table 4 Factors associated with discontinuation due to side-effects

\begin{tabular}{|c|c|c|c|}
\hline Parameter & $\begin{array}{l}\text { Parameter } \\
\text { estimates }\end{array}$ & $\begin{array}{c}\text { Odds } \\
\text { ratio }(95 \% \mathrm{CI})\end{array}$ & P-value \\
\hline Age at diagnosis & 0.02 & $1.02(0.97-1.07)$ & 0.32 \\
\hline $\begin{array}{l}\text { Sex } \\
\quad \text { Female } \\
\text { Male }\end{array}$ & $\begin{array}{c}-0.19 \\
\text { ref }\end{array}$ & $\begin{array}{c}0.81(0.36-1.84) \\
\text { ref }\end{array}$ & 0.62 \\
\hline $\begin{array}{l}\text { Race/Ethnicity } \\
\text { African American/ } \\
\text { non-Hispanic } \\
\text { Caucasian/Hispanic } \\
\text { Caucasian/ } \\
\text { non-Hispanic }\end{array}$ & $\begin{array}{c}0.008 \\
0.68 \\
\text { ref }\end{array}$ & $\begin{array}{l}1.00(0.40-2.54) \\
1.97(0.71-5.48) \\
\text { ref }\end{array}$ & $\begin{array}{l}0.98 \\
0.19\end{array}$ \\
\hline $\begin{array}{l}\text { Stage } \\
\text { Stage } 2 \\
\text { Stage } 3 \\
\text { Stage } 4\end{array}$ & $\begin{array}{c}0.28 \\
0.22 \\
\text { ref }\end{array}$ & $\begin{array}{c}1.32(0.39-4.42) \\
1.25(0.53-2.94) \\
\text { ref }\end{array}$ & $\begin{array}{c}0.64 \\
0.6\end{array}$ \\
\hline
\end{tabular}

Table 5 Factors associated with dose-reduction

\begin{tabular}{|c|c|c|c|}
\hline Parameter & $\begin{array}{l}\text { Parameter } \\
\text { estimates }\end{array}$ & $\begin{array}{c}\text { Odds } \\
\text { ratio }(95 \% \mathrm{CI})\end{array}$ & P-value \\
\hline Age at diagnosis & 0.01 & $1.01(0.96-1.06)$ & 0.51 \\
\hline $\begin{array}{l}\text { Sex } \\
\quad \text { Female } \\
\text { Male }\end{array}$ & $\begin{array}{c}-0.41 \\
\text { ref }\end{array}$ & $\begin{array}{c}0.65(0.25-1.68) \\
\text { ref }\end{array}$ & 0.38 \\
\hline $\begin{array}{l}\text { Race/Ethnicity } \\
\text { African American/ } \\
\text { non-Hispanic } \\
\text { Caucasian/Hispanic } \\
\text { Caucasian/ } \\
\text { non-Hispanic }\end{array}$ & $\begin{array}{c}1.76 \\
1.5 \\
\\
\text { ref }\end{array}$ & $\begin{array}{c}5.83(1.49-22.80) \\
4.49(1.09-18.42) \\
\text { ref }\end{array}$ & $\begin{array}{l}0.01 \\
0.03\end{array}$ \\
\hline $\begin{array}{l}\text { Stage } \\
\text { Stage } 2 \\
\text { Stage } 3 \\
\text { Stage } 4\end{array}$ & $\begin{array}{c}0.26 \\
0.57 \\
\text { ref }\end{array}$ & $\begin{array}{c}1.30(0.33-5.12) \\
1.77(0.66-4.74) \\
\text { ref }\end{array}$ & $\begin{array}{l}0.69 \\
0.25\end{array}$ \\
\hline
\end{tabular}

CI, confidence interval

toxicities were excluded to control for the confounding effects of previous and concomitant therapies.

While a prior study found no difference in skin toxicities between African Americans and Caucasians [33], our study-which evaluated only HFS, not overall skin toxicities-demonstrated a non-statistically significant $(\mathrm{P}=0.09)$ higher incidence of HFS in African American patients (OR 2.26, 95\%CI 0.86-5.95). This trend for more frequent HFS in African American patients may explain why they underwent more frequent dose reductions compared to Caucasians. We found that nearly $50 \%$ of patients with HFS had dose reductions, compared to only $25 \%$ of patients with diarrhea. A possible explanation for this difference is that lowgrade diarrhea is often controlled using pharmacological agents and does not require dose reductions, which is not the case with HFS. The twofold rate of HFS among African Americans compared to Caucasians and its contribution to capecitabine dose reductions should be evaluated in future studies.
Our study had several limitations. First, the small sample size may reduce the generalizability of the results and could be a reason why the estimate of risk for HFS did not attain statistical significance at $\mathrm{P}<0.05$. In addition, the retrospective review of the data and capturing toxicities based on clinical notes may have resulted in some misinterpretation. Since erythema may be masked in dark-skinned individuals, a few studies have suggested that the definition of lower grade HFS in African American individuals should be revised to also include hyperpigmentation of palms and soles [35,38]. We also did not evaluate medication adherence and its impact on sideeffects in our patients, as the data were not available. However, in the absence of large multi-center clinical trials that include diverse racial and ethnic population, our approach provides a "real-world" assessment of racial and ethnic differences in capecitabine toxicities. Future prospective studies will be necessary to evaluate pharmacogenetic factors contributing to differences in capecitabine toxicities, with documentation of severity of toxicities, time to toxicities, and resulting changes to doses or therapy, in different racial and ethnic minorities.

In summary, the findings of our study can help clinicians manage patients better, in the selection of treatment regimens and anticipation of different toxicities among different racial and ethnic populations. Our study further highlights a need for prospective evaluation of capecitabine toxicities in different racial and ethnic populations and their relationship with dose reductions and discontinuation of therapy.

\section{Summary Box}

\section{What is already known:}

- Capecitabine is associated with a number of serious side-effects, such as diarrhea and handfoot syndrome

- Racial and ethnic differences have been suggested as a factor in the occurrence of these capecitabine toxicities

- There is a lack of evidence assessing the association between these toxicities and patients from different racial/ethnic backgrounds

\section{What the new findings are:}

- As per our findings, African Americans were less likely to have diarrhea compared to Caucasians/ non-Hispanics

- Dose reductions due to side effects were higher in African Americans/non-Hispanics and Caucasian/ Hispanics compared to Caucasian/non-Hispanic

- Our study also suggests a need for prospective evaluation of capecitabine toxicities in different racial and ethnic populations, and their relationship with dose reductions and discontinuation of therapy 


\section{References}

1. Benson AB, Venook AP, Al-Hawary MM, et al. NCCN Guidelines Insights: Rectal Cancer, Version 6.2020. J Natl Compr Canc Netw 2020;18:806-815.

2. Ajani JA, D’Amico TA, Almhanna K, et al. Gastric Cancer, Version 3.2016, NCCN Clinical Practice Guidelines in Oncology. J Natl Compr Canc Netw 2016;14:1286-1312.

3. Engstrom PF, Arnoletti JP, Benson $A B$ 3 $3^{\text {rd }}$, et al; National Comprehensive Cancer Network. NCCN Clinical Practice Guidelines in Oncology: colon cancer. J Natl Compr Canc Netw 2009;7:778-831.

4. Brutcher E, Christensen D, Smith $\mathrm{MH}$, et al. 5-fluorouracil and capecitabine: assessment and treatment of uncommon early-onset severe toxicities associated with administration. Clin J Oncol Nurs 2018;22:627-634.

5. Xeloda (Package Insert), Genentech USA, Inc. South San Francisco, California; 2016.

6. Marse H, Cutsem EV, Grothey A, Valverde S. Management of adverse events and other practical considerations in patients receiving Capecitabine (Xeloda). Eur J Oncol Nurs 2004;8(Suppl 1):S16-S30.

7. Cassidy J, Twelves C, Van Cutsem E, et al; Capecitabine Colorectal Cancer Study Group. First-line oral capecitabine therapy in metastatic colorectal cancer: a favorable safety profile compared with intravenous 5-fluorouracil/leucovorin. Ann Oncol 2002;13:566-575.

8. Cunningham D, Lang I, Marcuello E, et al; AVEX study investigators. Bevacizumab plus capecitabine versus capecitabine alone in elderly patients with previously untreated metastatic colorectal cancer (AVEX): an open-label, randomised phase 3 trial. Lancet Oncol 2013;14:1077-1085.

9. Baird R, Biondo A, Chhaya V, et al. Toxicity associated with capecitabine plus oxaliplatin in colorectal cancer before and after an institutional policy of capecitabine dose reduction. $\mathrm{Br} J$ Cancer 2011;104:43-50.

10. Han HS, Reis IM, Zhao W, et al. Racial differences in acute toxicities of neoadjuvant or adjuvant chemotherapy in patients with earlystage breast cancer. Eur J Cancer 2011;47:2537-2545.

11. Fujii Y, Hirahara N, Kaji S, et al. Bevacizumab-induced intestinal perforation in a patient with inoperable breast cancer: a case report and review of the literature. J Med Case Rep 2018;12:84.

12. Doi T, Boku N, Kato K, et al. Phase I/II study of capecitabine plus oxaliplatin (XELOX) plus bevacizumab as first-line therapy in Japanese patients with metastatic colorectal cancer. Jpn J Clin Oncol 2010;40:913-920.

13. Check DK, Chawla N, Kwan ML, et al. Understanding racial/ ethnic differences in breast cancer-related physical well-being: the role of patient-provider interactions. Breast Cancer Res Treat 2018;170:593-603.

14. Xie HG, Kim RB, Wood AJ, Stein CM. Molecular basis of ethnic differences in drug disposition and response. Annu Rev Pharmacol Toxicol 2001;41:815-850.

15. Relling MV, Lin JS, Ayers GD, Evans WE. Racial and gender differences in N-acetyltransferase, xanthine oxidase, and CYP1A2 activities. Clin Pharmacol Ther 1992;52:643-658.

16. Klemetsdal B, Tollefsen E, Loennechen $\mathrm{T}$, et al. Interethnic difference in thiopurine methyltransferase activity. Clin Pharmacol Ther 1992;51:24-31.

17. Patel TA, Colon-Otero G, Bueno Hume C, Copland JA $3^{\text {rd }}$, Perez EA. Breast cancer in Latinas: gene expression, differential response to treatments, and differential toxicities in Latinas compared with other population groups. Oncologist 2010;15:466-475.

18. Trujillo-Paolillo A, Salinas-Souza C, Dias-Oliveira I, Petrilli AS, Toledo SRC. CYP genotypes are associated with toxicity and survival in osteosarcoma patients. J Adolesc Young Adult Oncol 2020;9:621-627.

19. Mattison L, Soong R, Diasio R. Implications of dihydropyrimidine dehydrogenase on 5-fluorouracil pharmacogenetics and pharmacogenomics. Pharmacogenomics 2002;3:485-492.
20. Saif MW. Dihydropyrimidine dehydrogenase gene (DPYD) polymorphism among Caucasian and non-Caucasian patients with 5-FU- and capecitabine-related toxicity using full sequencing of DPYD. Cancer Genomics Proteomics 2013;10:89-92.

21. Saif MW, Syrigos K, Mehra R, Mattison LK, Diasio RB. Dihydropyrimidine dehydrogenase deficiency (DPD) in GI malignancies: experience of 4-years. PakJ Med Sci 2007;23:832-839.

22. Meinsma R, Fernandez-Salguero P, Van Kuilenburg AB, Van Gennip AH, Gonzalez FJ. Human polymorphism in drug metabolism: mutation in the dihydropyrimidine dehydrogenase gene results in exon skipping and thymine uracilurea. DNA Cell Biol 1995;14:1-6.

23. Diasio RB, Beavers TL, Carpenter JT. Familial deficiency of dihydropyAQ1rimidine dehydrogenase. Biochemical basis for familial pyrimidinemia and severe 5-fluorouracil-induced toxicity. J Clin Invest 1988;81:47-51.

24. Harris BE, Carpenter JT, Diasio RB. Severe 5-fluorouracil toxicity secondary to dihydropyrimidine dehydrogenase deficiency. A potentially more common pharmacogenetic syndrome. Cancer 1991;68:499-501.

25. Lu Z, Zhang R, Diasio RB. Dihydropyrimidine dehydrogenase activity in human peripheral blood mononuclear cells and liver: population characteristics, newly identified deficient patients, and clinical implication in 5-fluorouracil chemotherapy. Cancer Res 1993;53:5433-5438.

26. Johnson MR, Diasio RB. Importance of dihydropyrimidine dehydrogenase (DPD) deficiency in patients exhibiting toxicity following treatment with 5-fluorouracil. Adv Enzyme Regul 2001;41:151-157.

27. Van Kuilenburg AB, Meinsma R, Zoetekouw L, Van Gennip AH. High prevalence of the IVS14 + 1G>A mutation in the dihydropyrimidine dehydrogenase gene of patients with severe 5-fluorouracil-associated toxicity. Pharmacogenetics 2002; 12:555-558.

28. Argilés G, Tabernero J, Labianca R, et al; ESMO Guidelines Committee. Electronic address: clinicalguidelines@esmo.org. Localised colon cancer: ESMO Clinical Practice Guidelines for diagnosis, treatment and follow-up. Ann Oncol 2020;31:1291-1305.

29. Dean L. Fluorouracil Therapy and DPYD Genotype. In: Pratt VM, McLeod HL, Rubinstein WS, et al. (editors). Medical Genetics Summaries. Bethesda (MD): National Center for Biotechnology Information (US); 2012.

30. Cunha-Junior GF, Bastos-Rodrigues L, Azevedo PG, et al. Prevalence of the DPYD variant (Y186C) in Brazilian individuals of African ancestry. Cancer Chemother Pharmacol 2019;84:1359-1363.

31. Mattison LK, Fourie J, Desmond RA, Modak A, Saif MW, Diasio RB. Increased prevalence of dihydropyrimidine dehydrogenase deficiency in African-Americans compared with Caucasians. Clin Cancer Res 2006;12:5491-5495.

32. Sohn DR, Cho MS, Chung PJ. Dihydropyrimidine dehydrogenase activity in a Korean population. Ther Drug Monit 1999;21:152-154.

33. Imaeda $M$, Sumi $S$, Ohba $S$, et al. Screening for pyrimidine metabolism disorders using dried filter-paper urine samples: method development and a pilot study in Nagoya City, Japan. Tohoku J Exp Med 2000;190:23-32.

34. McCollum AD, Catalano PJ, Haller DG, et al. Outcomes and toxicity in african-american and caucasian patients in a randomized adjuvant chemotherapy trial for colon cancer. J Natl Cancer Inst 2002;94:1160-1167.

35. Narasimhan P, Narasimhan S, Hitti IF, Rachita M. Serious handand-foot syndrome in black patients treated with capecitabine: report of 3 cases and review of the literature. Cutis 2004;73:101-106.

36. Moore S. Unanticipated toxicity to capecitabine. Oncol Nurs Forum 2009;36:149-152.

37. Pui JC, Meehan S, Moskovits T. Capecitabine induced cutaneous hyperpigmentation: report of a case. J Drugs Dermatol 2002;1:202-205.

38. Saif MW. Capecitabine and hand-foot syndrome. Expert Opin Drug Saf 2011;10:159-169. 